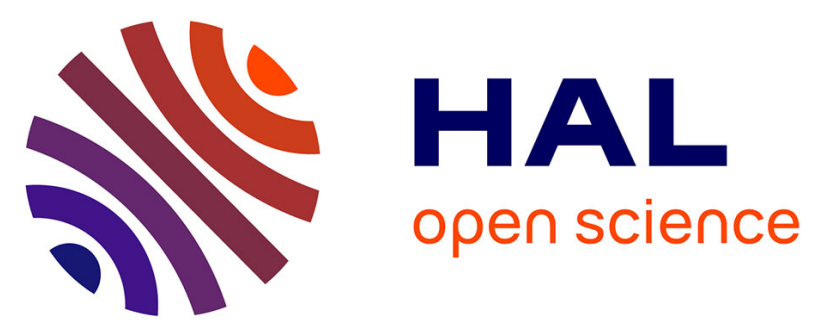

\title{
Letter to the Editor. Resting-state functional MRI for functional neurosurgery: seeing the light?
}

Constantin Tuleasca, Jean Regis, Elena Najdenovska, Tatiana Witjas, Nadine Girard, Jean-Philippe Thiran, Meritxell Bach Cuadra, Marc Levivier, Dimitri Van de Ville

\section{To cite this version:}

Constantin Tuleasca, Jean Regis, Elena Najdenovska, Tatiana Witjas, Nadine Girard, et al.. Letter to the Editor. Resting-state functional MRI for functional neurosurgery: seeing the light?. Journal of Neurosurgery, inPress, 10.3171/2019.1.JNS1995 . hal-02179353

\section{HAL Id: hal-02179353 https://hal.sorbonne-universite.fr/hal-02179353}

Submitted on 10 Jul 2019

HAL is a multi-disciplinary open access archive for the deposit and dissemination of scientific research documents, whether they are published or not. The documents may come from teaching and research institutions in France or abroad, or from public or private research centers.
L'archive ouverte pluridisciplinaire HAL, est destinée au dépôt et à la diffusion de documents scientifiques de niveau recherche, publiés ou non, émanant des établissements d'enseignement et de recherche français ou étrangers, des laboratoires publics ou privés. 


\title{
Resting-state Functional MRI for Functional Neurosurgery: Seeing the Light?
}

\author{
Constantin Tuleasca ${ }^{1,2,3,4,5}$, MD-PhD, Jean Régis ${ }^{6}, \mathrm{MD}$, Elena Najdenovska ${ }^{7}, \mathrm{PhD}$, Tatiana \\ Witjas $^{8}, \mathrm{MD}$, Nadine Girard ${ }^{9}$, MD, Jean-Philippe Thiran ${ }^{2,3,10}$, PhD, Meritxell Bach Cuadra ${ }^{3,7}$, \\ PhD, Marc Levivier ${ }^{1,2}$, MD, PhD, IFAANS, AND Dimitri Van De Ville ${ }^{11,12}, \mathrm{PhD}$ \\ ${ }^{1}$ Neurosurgery Service and Gamma Knife Center, Lausanne University Hospital (CHUV), Lausanne, \\ Switzerland \\ ${ }^{2}$ Université de Lausanne (Unil), Faculté de Biologie et de Médecine (FBM); \\ ${ }^{3}$ Signal Processing Laboratory (LTS 5), Swiss Federal Institute of Technology (EPFL); \\ ${ }^{4}$ Sorbonné Université, Faculté de Médecine, Paris, France; \\ ${ }^{5}$ Assisstance Publique-Hôpitaux de Paris, Hôpitaux Universitaires Paris Sud, Centre Hospitalier Universitaire de \\ Bicêtre, Service de Neurochirurgie, Le Kremlin-Bicêtre, France; \\ ${ }^{6}$ Stereotactic and Functional Neurosurgery Service and Gamma Knife Unit, CHU Timone, Marseille, France; \\ ${ }^{7}$ Medical Image Analysis Laboratory (MIAL) and Department of Radiology-Center of Biomedical Imaging \\ (CIBM), Centre Hospitalier Universitaire Vaudois, Lausanne, Switzerland; \\ ${ }^{8}$ Neurology Department, CHU Timone, Marseille, France; \\ ${ }^{9}$ AMU, CRMBM UMR CNRS 7339, Faculté de Médecine and APHM, Hopital Timone, Department of \\ Diagnostic and Interventionnal Neuroradiology, Marseille; \\ ${ }^{10}$ Centre Hospitalier Universitaire Vaudois, Department of Radiology; \\ ${ }^{11}$ University of Geneva, Faculty of Medicine, Switzerland; \\ ${ }^{12}$ Medical Image Processing Laboratory, Ecole Polytechnique Fédérale de Lausanne (EPFL), Switzerland; \\ \# of abstract words : N/A \\ \# of text words : 335 \\ \# of references : 10 \\ \# of tables/figures : 1 figure \\ \# of videos : 0
}

Running title: Resting-state fMRI for functional neurosurgery

Key words: functional, neurosurgery, resting-state, functional MRI, tremor

\section{Corresponding author:}

Constantin Tuleasca, MD-PhD, Assisstance Publique-Hôpitaux de Paris, Hôpitaux Universitaires Paris Sud, Centre Hospitalier Universitaire de Bicêtre, Service de Neurochirurgie, Le Kremlin-Bicêtre, France- 78, Rue Général Leclerc, 94270, Le Kremlin-Bicêtre, France; Sorbonné Université, Faculté de Médecine, Paris, France; Tel: +41-21-314-26-02; Fax: +41-21-314-11-99; e-mail: constantin.tuleasca@gmail.com;

Financial Disclosures: None 
Dear Editor,

We read with great interest the recent article by Lehner ${ }^{5}$ et al., discussing the corpus callosotomy performed by laser interstitial thermal therapy (LITT), in a small cohort of 5 patients, in the context of a multimodal approach. The authors additionally used resting-state functional MRI (rs-fMRI) to assess the outcome of this functional neurosurgery intervention. While prior to LITT brain activity showed robust interhemispheric functional connectivity, it was greatly reduced following callosotomy, with intrahemispherical functional connectivity being largely maintained.

Understanding how brain rewiring after functional neurosurgery procedures impacts brain activity is essential for our understanding and for providing future developments in this extraordinary and continuously expanding field. In that context, rs-fMRI is particularly useful given its possibility to map various functional networks simultaneously with minimal patient compliance.

Boerwinkle et $\mathrm{al}^{1}$ have recently suggested that using rs-fMRI might improve outcomes using MRI-guided stereotactic laser ablation for hypothalamic hamartomas. We have demonstrated before how stereotactic radiosurgical thalamotomy for drug-resistant essential tremor (ET) correlates with changes within large-scale brain networks (Figure 1$)^{6-10}$. Comparison of pre- and post-inventional imaging allowed confirming the role of the ventrointermediate nucleus target region in the tremor network ${ }^{7,8}$. Then, more surprisingly, a visually-sensitive structural and functional network was shown to be involved in tremor generation and further arrest after the intervention, thus pointing towards potential new surgical targets for tremor such as the right extrastriate visual cortex ${ }^{6,7,9,10}$. We specifically coined the term "cerebello-thalamo-visuo-motor network» ${ }^{7}$ to describe these observations ${ }^{2}$. In trigeminal neuralgia, Dou et $\mathrm{al}^{3}$ demonstrated how a specific measure of functional connectivity (e.g., regional homogeneity), would change in specific parts of the brain after percutaneous radiofrequency thermocoagulation. More recently, Fox and colleagues elegantly discussed how relating symptoms with brain connectomics leads to lesion network mapping ${ }^{4}$.

In conclusion, an important expenditure of rs-fMRI is its further application to interventional studies in clinical realm, particularly, in the functional neurosurgery domain. Whether this would allow us to see the light for better understanding of both the pre- and post-therapeutic state remains also to be confirmed by future studies. 
Funding: The work was supported by the Swiss National Science Foundation (SNSF-205321157040) and by the Centre d'Imagerie BioMédicale (CIBM) of the University of Lausanne (UNIL), the Swiss Federal Institute of Technology Lausanne (EPFL), the University of Geneva (UniGe), the Centre Hospitalier Universitaire Vaudois (CHUV), the CHU Timone, Marseille, France; the Hôpitaux Universitaires de Genève (HUG), and the Leenaards and Jeantet Foundations.

Acknowledgments: Lausanne and Marseille University Hospitals.

Conflict of interest: No conflict of interest. 


\section{References:}

1. Boerwinkle VL, Foldes ST, Torrisi SJ, Temkit H, Gaillard WD, Kerrigan JF, et al: Subcentimeter epilepsy surgery targets by resting state functional magnetic resonance imaging can improve outcomes in hypothalamic hamartoma. Epilepsia 59:2284-2295, 2018

2. Chiang VL, Chao ST, Tuleasca C, Foote MC, Lee CC, Mathieu D, et al: Proceedings of the 2018 next-generation Gamma Knife research meeting. J Neurosurg 129:5-9, 2018

3. Dou Z, Zhang X, Yang L, Wang W, Li N, Liu Z, et al: Alternation of regional homogeneity in trigeminal neuralgia after percutaneous radiofrequency thermocoagulation: A resting state fMRI study. Medicine (Baltimore) 95:e5193, 2016

4. Fox MD: Mapping Symptoms to Brain Networks with the Human Connectome. $\mathbf{N}$ Engl J Med 379:2237-2245, 2018

5. Lehner KR, Yeagle EM, Argyelan M, Klimaj Z, Du V, Megevand P, et al: Validation of corpus callosotomy after laser interstitial thermal therapy: a multimodal approach. J Neurosurg:1-11, 2018

6. Tuleasca C, Najdenovska E, Regis J, Witjas T, Girard N, Champoudry J, et al: Clinical response to Vim's thalamic stereotactic radiosurgery for essential tremor is associated with distinctive functional connectivity patterns. Acta Neurochir (Wien), 2018

7. Tuleasca C, Najdenovska E, Regis J, Witjas T, Girard N, Champoudry J, et al: Pretherapeutic Motor Thalamus Resting-State Functional Connectivity with Visual Areas Predicts Tremor Arrest After Thalamotomy for Essential Tremor: Tracing the Cerebello-thalamo-visuo-motor Network. World Neurosurg, 2018

8. Tuleasca C, Najdenovska E, Regis J, Witjas T, Girard N, Champoudry J, et al: Ventrolateral Motor Thalamus Abnormal Connectivity in Essential Tremor Before and After Thalamotomy: A Resting-State Functional Magnetic Resonance Imaging Study. World Neurosurg, 2018

9. Tuleasca C, Regis J, Levivier M: Essential Tremor. N Engl J Med 379:595-596, 2018

10. Tuleasca C, Regis J, Najdenovska E, Witjas T, Girard N, Thiran JP, et al: Visuallysensitive networks in essential tremor: evidence from structural and functional imaging. Brain, 2018 


\section{Figure legend:}

Figure 1: Upper part, from left to right: artistic representation of Vim SRS-T; structural MRI alterations within Brodmann areas (BA) 19 and further 18 as depicted by structural (voxel-based morphometry) studies by our group; functional resting-state fMRI changes, using different methodologies, such as independent component analysis and seed-to-voxel; Lower part, left- artistic illustration of the eye-hand coordination, necessary for sensory guidance of movements, as a new concept for tremor generation in ET; right- artistic illustration suggesting the extrastriate cortex as a new potential target for drug-resistant ET.

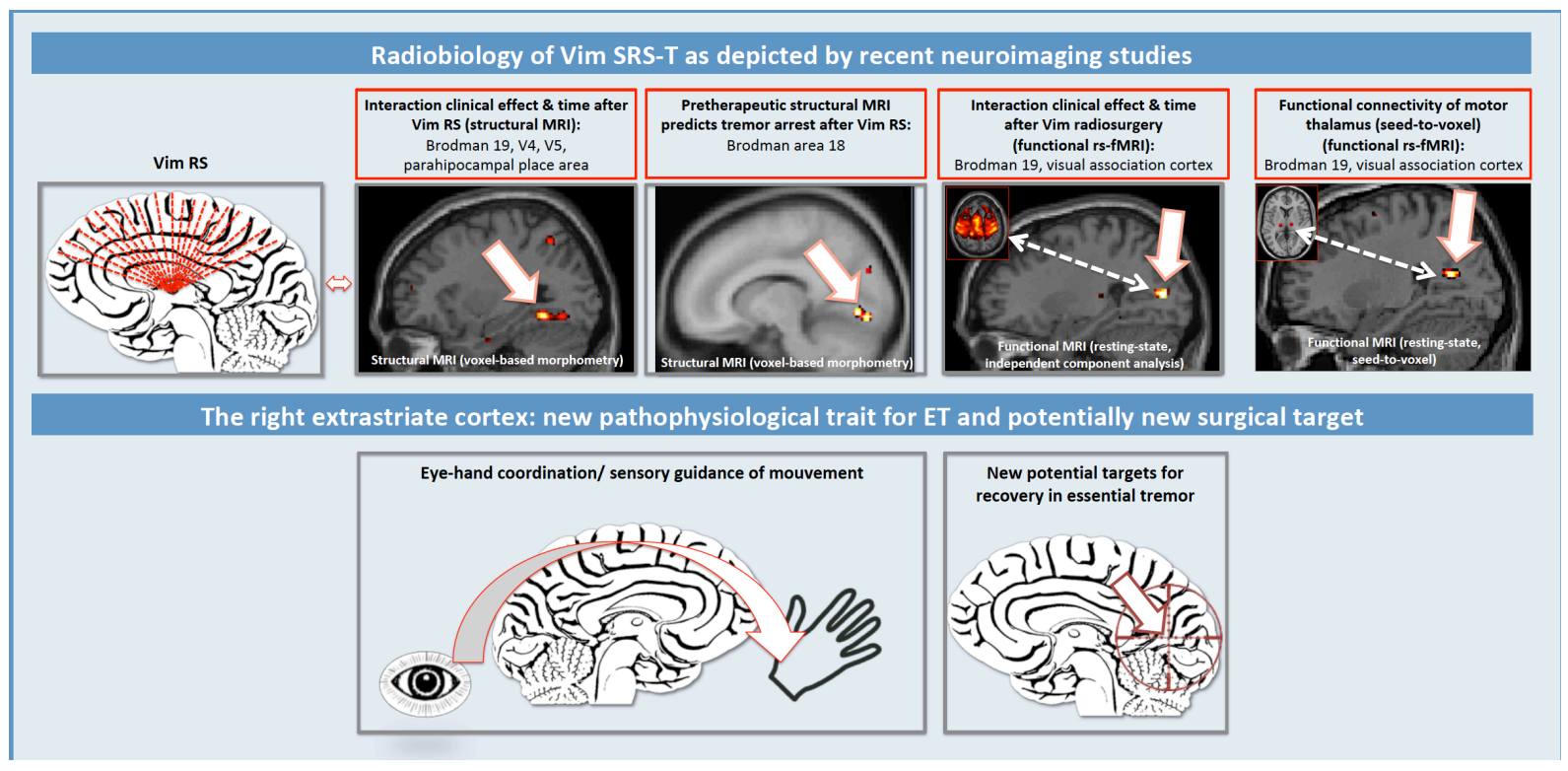

